\title{
openheart Left ventricular diastolic reserve in patients with type 2 diabetes mellitus
}

\author{
Melissa Leung, ${ }^{1}$ Victoria Phan, ${ }^{1}$ Melinda Whatmough, ${ }^{1}$ Stephane Heritier, ${ }^{2}$ \\ Vincent W Wong, ${ }^{3,4}$ Dominic $Y$ Leung ${ }^{1}$
}

To cite: Leung M, Phan V, Whatmough $M$, et al. Left ventricular diastolic reserve in patients with type 2 diabetes mellitus. Open Heart 2015;2: e000214. doi:10.1136/ openhrt-2014-000214

Received 26 October 2014 Revised 28 January 2015 Accepted 4 March 2015
CrossMark

\footnotetext{
${ }^{1}$ Department of Cardiology, Liverpool Hospital, University of New South Wales, Sydney, New South Wales, Australia ${ }^{2}$ The George Institute, University of Sydney, Camperdown, New South Wales, Australia

${ }^{3}$ Liverpool Diabetes

Collaborative Research Unit, Ingham Institute, Liverpool, Sydney, New South Wales, Australia

${ }^{4}$ University of New South Wales, Sydney, New South Wales, Australia
}

Correspondence to Dr Melissa Leung; melissa@unsw.edu.au

\section{ABSTRACT}

Aims: Diastolic reserve is the ability of left ventricular filling pressures to remain normal with exercise. Impaired diastolic reserve may be an early sign of diabetic cardiomyopathy. We aimed to determine whether diastolic reserve differs in type 2 diabetes (DM) compared with non-DM, and to identify clinical, anthropological, metabolic and resting echocardiographic correlates of impaired diastolic reserve in patients with DM.

Methods and results: 237 patients (aged 53 \pm 11 years, $133 \mathrm{DM}$, ejection fraction $68 \pm 9 \%$ ) underwent rest and exercise echocardiography. Mitral $\mathrm{E}$ and septal $\mathrm{e}^{\prime}$ were measured at rest, immediately post, and 10 min into recovery. Analysis of covariance (ANCOVA) and binary regression with continuous outcomes were used to model $\mathrm{e}^{\prime}$ and E/e' changes with exercise to identify impaired diastolic reserve defined as post-exercise E/e $\mathrm{e}^{\prime} \geq 15$.

After adjusting for baseline differences, patients with DM immediately post-exercise had a lower septal $\mathrm{e}^{\prime}, \mathrm{a}$ lower $\Delta \mathrm{e}^{\prime}(1.2 \mathrm{vs} 2.3 \mathrm{~cm} / \mathrm{s}, \mathrm{p}=0.006)$ and a higher $\Delta$ septal E/e' $(1.7$ vs $0.08, p<0.001)$ than patients without DM. In patients with normal resting $E / e^{\prime}$ of $\leq 8(n=130)$, DM had a significantly higher post-exercise septal $E / \mathrm{e}^{\prime}$ and a higher $\Delta$ septal $E / e^{\prime}$ (2.63 vs $\left.0.50, p<0.001\right)$. E/e' in patients with DM remained significantly elevated up to 10 min post-exercise. Hypertension, longer duration of insulin therapy, poorer glycaemic control, worse renal function, larger left atrial volume and lower septal $\mathrm{e}^{\prime}$ were independent correlates of impaired diastolic reserve in patients with DM.

Conclusions: Patients with DM have impaired diastolic reserve manifest as a blunted $\mathrm{e}^{\prime}$ response with exercise, persisting into recovery. Clinical, anthropometric, metabolic and echocardiographic correlates of impaired diastolic reserve in patients with DM were identified. An impaired LV diastolic reserve may be the underlying pathophysiological mechanism in patients with DM with unexplained exertional dyspnoea and may allow earlier detection of DM cardiomyopathy.

\section{INTRODUCTION}

Patients with type 2 diabetes mellitus (DM) may develop cardiomyopathy independent of traditional risk factors such as hypertension and epicardial coronary artery disease (CAD). The spectrum of myocardial

\section{KEY MESSAGES}

What is already known about this subject?

- Patients with type 2 diabetes mellitus (DM) may develop cardiomyopathy independent of traditional risk factors such as hypertension and epicardial coronary artery disease. Left ventricular (LV) diastolic dysfunction is an early manifestation. Exercise echocardiography can unmask diastolic dysfunction in patients with exertional dyspnoea.

What does this study add?

- Patients with DM had impaired diastolic reserve manifest as a blunted $\mathrm{e}^{\prime}$ response with exercise, persisting into recovery. Clinical, anthropometric, metabolic and echocardiographic correlates of impaired diastolic reserve in patients with DM were identified.

How might this impact on clinical practice?

- An impaired LV diastolic reserve may be the underlying pathophysiological mechanism in patients with DM with unexplained exertional dyspnoea and may allow earlier detection of DM cardiomyopathy.

dysfunction may range from subclinical left ventricular (LV) diastolic and systolic dysfunction through to overt systolic dysfunction. Patients may initially be asymptomatic, progressing to exertional dyspnoea, followed by overt symptomatic heart failure in advanced stages of the disease. ${ }^{1}$

Elevation in LV filling pressures is the underlying pathophysiology leading to exertional dyspnoea in patients with LV systolic or diastolic dysfunction. LV filling pressures can be reliably estimated non-invasively with transthoracic echocardiography from the mitral E wave velocity with pulsed wave Doppler to mitral annulus tissue Doppler $\mathrm{e}^{\prime}$ velocity ratio. ${ }^{2}$ Diastolic reserve is the ability of the LV to augment diastolic function to maintain normal filling pressures with tachycardia such as that seen during exercise. Analogous to an impaired contractile reserve in latent LV systolic dysfunction, an impaired diastolic 
reserve may be seen in early stages of diastolic dysfunction such as that seen in diabetic cardiomyopathy. Previous studies have demonstrated the utility of exercise echocardiography in evaluating patients with exertional dyspnoea to unmask diastolic dysfunction. ${ }^{3-5}$ Few studies have specifically looked at its utility in estimating LV filling pressures with exercise in patients with DM. The correlates of an impaired LV diastolic reserve in type 2 DM are unclear. Furthermore, no studies have examined the behaviour of LV filling pressures into the recovery period after exercise in such patients. Examining diastolic reserve and its behaviour post-exercise into recovery may allow even earlier detection of diabetic cardiomyopathy in patients with apparently normal resting LV systolic and diastolic function with normal LV filling pressures at rest. In this study, we aim to determine whether diastolic reserve differs in type $2 \mathrm{DM}$ compared with non-DM and, if so, identify clinical, anthropometric, metabolic and resting echocardiographic correlates of impaired diastolic reserve in patients with DM.

\section{MATERIAL AND METHODS \\ Patients}

Two hundred and thirty-nine consecutive subjects (133 patients with type $2 \mathrm{DM}, 149$ men, aged $53 \pm 11$ years) referred for cardiovascular assessment at the hospital clinic were prospectively recruited. Patients with type 1 $\mathrm{DM}$, known congenital, valvular or $\mathrm{CAD}$, severe hypertension (systolic pressure $>200 \mathrm{~mm} \mathrm{Hg}$ and diastolic pressure $>120 \mathrm{~mm} \mathrm{Hg}$ at rest), left bundle branch block, rhythm other than sinus and those unable to exercise were excluded. All participants had a normal resting ECG. All cardiac medications were continued throughout the study with no modifications made to the patients' treatment regimen. All patients provided written informed consent. The study was approved by the Hospital Human Ethics Committee.

Clinical data collected included anthropometric, cardiac risk factors, duration of DM, medications and presence of macrovascular and microvascular complications. All participants ranked their degree of breathlessness from 1 to 5 using the Medical Research Council (MRC) dyspnoea scale. ${ }^{6}$

\section{Metabolic data}

All participants recruited had been screened for diabetes by their family physicians. For patients with DM, haemoglobin, glycated haemoglobin (HbAlc) levels, serum creatinine, estimated glomerular filtration rate (eGFR) using the Modification of Diet in Renal Disease (MDRD) formula, ${ }^{7}$ complete lipid profile and urinary spot albumin to creatinine ratio were measured.

\section{Echocardiography protocols}

All patients underwent rest echocardiography followed by symptom limited exercise echocardiography.

\section{Two-dimensional and Doppler echocardiography}

Two-dimensional transthoracic echocardiography was performed in the left lateral decubitus position with commercially available ultrasound equipment (M5S probe, Vivid E9, GE Medical Systems, Milwaukee, Wisconsin). All images were digitally stored on hard discs for offline analysis (EchoPAC, BT10, GE). A complete M-mode, two-dimensional (2D), colour, pulsed and continuous-wave Doppler examination was performed according to standard techniques at rest to assess chamber thickness, volumes and valvular morphology.

LV diastolic and systolic volumes were measured to calculate LV ejection fraction using the Simpson biplane method of discs in the apical four-chamber and twochamber views. Maximum left atrial (LA) volumes were measured similarly. The mitral inflow pattern was interrogated with pulse wave Doppler by placing a 1-2 mm sample volume at the mitral leaflet tips in the apical four-chamber view. The peak velocities of early (E) and late (A) ventricular filling, and deceleration times of the $\mathrm{E}$ wave were measured.

Mitral septal and lateral annulus systolic $\left(\mathrm{s}^{\prime}\right)$, early $\left(\mathrm{e}^{\prime}\right)$ and late $\left(\mathrm{a}^{\prime}\right)$ diastolic tissue velocities were measured with pulse-wave tissue Doppler. The Nyquist limit was adjusted to approximately $24 \mathrm{~cm} / \mathrm{s}$, and a clear tissue signal with minimal background noise was recorded by optimising the gain and sample volume. A 2-5 mm sample volume was placed at the septal and lateral mitral annulus in the apical four-chamber view, with careful attention to ensure proper alignment and minimise the incident angle. Three to five cardiac cycles were recorded for all 2D echocardiographic and Doppler measurements and the average values were used.

\section{Exercise echocardiography}

All patients underwent symptom-limited exercise echocardiography on a treadmill protocol according to the patients' individual physical ability. Heart rate and blood pressure were measured at rest and every three minutes during exercise. Two-dimensional images of the LV were obtained in the apical (4-chamber, 2-chamber, long axis), parasternal long-axis and mid-ventricular short-axis views. These images were taken at rest, immediately postexercise, and $5 \mathrm{~min}$ and $10 \mathrm{~min}$ post-exercise.

Immediately after the acquisition of $2 \mathrm{D}$ images postexercise, the mitral $\mathrm{E}$ wave velocities and mitral septal annulus systolic $\left(\mathrm{s}^{\prime}\right)$, early $\left(\mathrm{e}^{\prime}\right)$ and late $\left(\mathrm{a}^{\prime}\right)$ diastolic tissue velocities were measured immediately after the acquisition of the 2D images, and again at $5 \mathrm{~min}$ and 10 min post-exercise. Patients with inducible ischaemia evident by new LV segmental wall motion abnormalities were excluded from further analysis $(n=2)$.

Mitral $\mathrm{E} / \mathrm{e}^{\prime}$ ratio was used to estimate LV filling pressures at rest and post-exercise. An impaired LV diastolic reserve was defined as a post-exercise $\mathrm{E} / \mathrm{e}^{\prime} \geq 15$ indicating elevated LV filling pressures. 


\section{Statistical analysis}

Continuous variables were presented as mean $\pm 1 \mathrm{SD}$ unless otherwise stated. Continuous variables were compared with the Student $\mathrm{t}$ test. Analysis of covariance (ANCOVA) was used to model $\mathrm{e}^{\prime}$ and $\mathrm{E} / \mathrm{e}^{\prime}$ changes with exercise and into recovery. Binary regression with continuous outcomes $(\mathrm{BRCO})^{8}$ was performed to identify correlates of an impaired diastolic reserve in patients with DM. This method is more powerful than logistic regression as it directly models the risk of $\mathrm{E} / \mathrm{e}^{\prime} \geq 15$ on the logit scale without dichotomising. BRCO takes into account the fact that values that lie further away from the cut-off bring more information than values that are close, and hence there is a gain in power compared with the dichotomous approach. ${ }^{9}$ Univariate analyses were first performed to determine potential correlates among clinical, anthropological, metabolic and echocardiographic variables. Model building was done in three steps using the Akaike Information Criterion (AIC) to select the 'best' model at each step. First, the 'base clinical model' was determined using only clinical and anthropological variables. Then the metabolic parameters were added to the base clinical model to build the 'clinical and metabolic model. Echocardiographic parameters were similarly added to the 'clinical and metabolic' model to establish a 'clinical, metabolic and echocardiographic' model. This three-step strategy was implemented to determine the incremental value of metabolic and echocardiographic parameters to clinical factors alone in predicting immediate post-exercise $\mathrm{E} / \mathrm{e}^{\prime}$. Specifically, 10-fold cross-validated receiver operating characteristic (ROC) curves were constructed for the three BRCO models identified above to determine their predictive ability of a post-exercise $\mathrm{E} / \mathrm{e}^{\prime} \geq 15 .{ }^{10}$ MRC dyspnoea grade was not entered into the BRCO analysis as we intended to identify objectively defined and measured clinical, metabolic and resting echocardiographic correlates of elevated post-exercise $\mathrm{E} / \mathrm{e}^{\prime}$. A separate linear regression was performed to examine the relationship between post-exercise $\mathrm{E} / \mathrm{e}^{\prime}$ and MRC dyspnoea grade to examine if elevated post-exercise $\mathrm{E} / \mathrm{e}^{\prime}$ measured with echocardiography translated into patients' subjective symptoms of exertional dyspnoea. A two-sided $\mathrm{p}$ value $<0.05$ was considered significant. Statistical analyses were performed using STATA V.12 (STATA Corporation, Texas, USA) and R V.3.0 Statistical Software (Foundation for Statistical Computing, Austria).

\section{RESULTS}

Baseline clinical, anthropological and echocardiographic characteristics of our 237 included patients are presented in table 1 .

\section{Patients with diabetes}

There were 133 patients with type 2 DM. Ninety patients $(68 \%)$ had an MRC dyspnoea grade $>1$. The mean duration of DM was $11 \pm 7$ years with a mean HbA1c of 8.9 $\pm 2.2 \%$. Sixty-six patients $(50 \%)$ required insulin therapy. Seventy-four patients $(59 \%)$ had microalbuminuria and $24(18 \%)$ had Kidney Disease Outcomes Quality Initiative (KDOQI) stage 3 or more advanced kidney disease (eGFR $\left.<60 \mathrm{~mL} / \mathrm{kg} / 1.73 \mathrm{~m}^{2}\right) .{ }^{11} \quad$ Thirty-one patients $(27 \%)$ had retinopathy and $30(26 \%)$ had peripheral neuropathy. Compared with patients without DM, patients with DM were older, with a higher body weight, body surface area and body mass index. They had a higher prevalence of hypertension and hypercholesterolemia and more patients were on antiplatelet and other cardioactive medications (table 1). More patients in the diabetes group reported exertional dyspnoea.

\section{Baseline echocardiographic characteristics}

The differences in baseline echocardiographic characteristics of patients with DM compared with patients without DM are summarised in table 1. Patients with DM had smaller LV systolic volumes and hence a higher LV ejection fraction, a lower septal $\mathrm{e}^{\prime}$ and hence a higher septal E/e'.

\section{Haemodynamic response to exercise}

Two patients had inducible ischaemia on stress echocardiography and were excluded from subsequent analysis and all participants maintained sinus rhythm throughout the study. Table 1 summarises the haemodynamic responses of patients with DM compared with patients without. The mean exercise duration was $9 \pm 4$ min. After adjusting for baseline differences, patients with DM immediately post-exercise had a lower septal $\mathrm{e}^{\prime}$, a lower $\Delta \mathrm{e}^{\prime}(1.2 \mathrm{vs} 2.3 \mathrm{~cm} / \mathrm{s}, \mathrm{p}=0.006)$ and a higher $\Delta$ septal E/ $/ \mathrm{e}^{\prime}$ ( 1.7 vs $0.08, \mathrm{p}<0.001)$.

In patients with normal resting $\mathrm{E} / \mathrm{e}^{\prime}$ of $\leq 8 \quad(\mathrm{n}=130)$, patients with DM immediately post-exercise had a significantly higher septal $\mathrm{E} / \mathrm{e}^{\prime}$ and a higher $\Delta$ septal $\mathrm{E} / \mathrm{e}^{\prime}$ (table 2).

Figure 1 shows the profile of LV diastolic function parameters in patients with DM compared with patients without DM at rest, immediately post-exercise and 10 min into recovery. Patients with DM had a similar pattern of rise in mitral inflow $\mathrm{E}$ wave velocity, but a blunted $\mathrm{e}^{\prime}$ response to exercise, which resulted in a significantly elevated $\mathrm{E} / \mathrm{e}^{\prime}$ in patients with $\mathrm{DM}$. E/e' immediately post-exercise in patients with $\mathrm{DM}$ remained significantly elevated up to $10 \mathrm{~min}$ post-exercise.

In patients with resting $\mathrm{E} / \mathrm{e}^{\prime}$ between 8 and 15 , patients with $\mathrm{DM}$ also had a significantly higher $\mathrm{E} / \mathrm{e}^{\prime}$ immediately post-exercise, whereas for patients with elevated rest $\mathrm{E} / \mathrm{e}^{\prime} \geq 15$, the immediate post-exercise $\mathrm{E} / \mathrm{e}^{\prime}$ was similar for both DM and non-DM (table 2).

There was a significant linear relationship between MRC dyspnoea grade and log transformed post-exercise septal E $/ \mathrm{e}^{\prime}(\beta=0.21, \mathrm{p}<0.001)$ for all patients. Similarly, a significant relationship was also seen in patients with DM $(\beta=0.18, p<0.001)$. 
Table 1 Baseline clinical, resting echocardiographic characteristics and exercise responses of the patients with diabetes compared with patients without diabetes

\begin{tabular}{|c|c|c|c|}
\hline & Diabetes $(n=133)$ & No diabetes $(n=104)$ & p Value \\
\hline \multicolumn{4}{|l|}{ Clinical and anthropological characteristics } \\
\hline Age (years) & $54 \pm 10$ & $50 \pm 12$ & 0.005 \\
\hline Male & $90(68 \%)$ & $59(57 \%)$ & 0.084 \\
\hline Height $(\mathrm{cm})$ & $168 \pm 9$ & $167 \pm 14$ & 0.689 \\
\hline Weight (kg) & $91 \pm 21$ & $77 \pm 17$ & $<0.001$ \\
\hline Body surface area $\left(\mathrm{m}^{2}\right)$ & $2.04 \pm 0.27$ & $1.90 \pm 0.26$ & $<0.001$ \\
\hline Body mass index $\left(\mathrm{kg} / \mathrm{m}^{2}\right)$ & $32 \pm 7$ & $28 \pm 14$ & 0.0061 \\
\hline Smoking (n (\%)) & $22(17 \%)$ & $18(17 \%)$ & 0.876 \\
\hline Hypertension (n (\%)) & $93(70 \%)$ & $34(33 \%)$ & $<0.001$ \\
\hline Dyslipidemia (n (\%)) & $106(80 \%)$ & $39(38 \%)$ & $<0.001$ \\
\hline Family history CAD (n (\%)) & $35(26 \%)$ & $34(33 \%)$ & 0.284 \\
\hline Antiplatelet agent (n (\%)) & $50(38 \%)$ & $16(15 \%)$ & $<0.001$ \\
\hline$\beta$-blocker (n (\%)) & $24(18 \%)$ & $8(8 \%)$ & 0.021 \\
\hline Calcium channel blocker ( $\mathrm{n}(\%))$ & $24(18 \%)$ & $4(4 \%)$ & 0.001 \\
\hline ACE inhibitor (n (\%)) & $53(40 \%)$ & $3(3 \%)$ & $<0.001$ \\
\hline Angiotensin receptor blocker (n (\%)) & $43(32 \%)$ & $14(13 \%)$ & 0.001 \\
\hline Diuretics (n (\%)) & $22(17 \%)$ & $8(8 \%)$ & 0.042 \\
\hline Statin (n (\%)) & $86(63 \%)$ & $31(30 \%)$ & $<0.001$ \\
\hline MRC dyspnoea grade & & & $<0.001$ \\
\hline 1 & $43(32 \%)$ & $67(65 \%)$ & \\
\hline 2 & $68(51 \%)$ & $31(30 \%)$ & \\
\hline 3 & $14(11 \%)$ & $3(3 \%)$ & \\
\hline 4 & $8(6 \%)$ & $2(2 \%)$ & \\
\hline 5 & $0(0 \%)$ & $0(0 \%)$ & \\
\hline \multicolumn{4}{|l|}{ Resting LV parameters } \\
\hline LV end-diastolic volume index $\left(\mathrm{mL} / \mathrm{m}^{2}\right)$ & $35 \pm 24$ & $39 \pm 11$ & 0.233 \\
\hline LV end-systolic volume index $\left(\mathrm{mL} / \mathrm{m}^{2}\right)$ & $10 \pm 6$ & $14 \pm 7$ & $<0.001$ \\
\hline Resting LV ejection fraction (\%) & $70 \pm 10$ & $66 \pm 9$ & $<0.001$ \\
\hline Septal s' (cm/s) & $7.0 \pm 1.6$ & $7.4 \pm 1.5$ & 0.056 \\
\hline Septal e' (cm/s) & $7.0 \pm 2.0$ & $8.9 \pm 2.7$ & $<0.001$ \\
\hline Septal E/e' & $10.5 \pm 4.6$ & $8.2 \pm 2.5$ & $<0.001$ \\
\hline Lateral E/e' & $8.6 \pm 4.5$ & $7.0 \pm 2.9$ & 0.012 \\
\hline LV mass index $\left(\mathrm{g} / \mathrm{m}^{2}\right)$ & $80 \pm 20$ & $82 \pm 20$ & 0.447 \\
\hline \multicolumn{4}{|l|}{ Resting left atrial parameters } \\
\hline Maximum LA volume index $\left(\mathrm{mL} / \mathrm{m}^{2}\right)$ & $29 \pm 7$ & $28 \pm 8$ & 0.220 \\
\hline \multicolumn{4}{|l|}{ Post-exercise echocardiographic parameters } \\
\hline LV end-diastolic volume index $\left(\mathrm{mL} / \mathrm{m}^{2}\right)$ & $80 \pm 28$ & $79 \pm 27$ & 0.879 \\
\hline LV end-systolic volume index $\left(\mathrm{mL} / \mathrm{m}^{2}\right)^{\prime}$ & $22 \pm 15$ & $22 \pm 12$ & 0.931 \\
\hline LV ejection fraction (\%) & $74 \pm 10$ & $73 \pm 9$ & 0.477 \\
\hline Septal s' (cm/s) & $11.5 \pm 3.3$ & $12.8 \pm 3.5$ & 0.006 \\
\hline Septal e' (cm/s) & $8.0 \pm 2.4$ & $11.3 \pm 3.3$ & $<0.001$ \\
\hline$\Delta \mathrm{e}^{\prime}(\mathrm{cm} / \mathrm{s})$ & $1.0 \pm 1.9$ & $2.4 \pm 2.8$ & $<0.001$ \\
\hline Septal E/e' & $12.6 \pm 4.7$ & $8.2 \pm 2.5$ & $<0.001$ \\
\hline$\Delta$ Septal E/e' & $2.12 \pm 3.4$ & $0.04 \pm 2.0$ & $<0.001$ \\
\hline Septal $a^{\prime}(\mathrm{cm} / \mathrm{s})$ & $13.3 \pm 3.3$ & $14.1 \pm 3.5$ & 0.051 \\
\hline \multicolumn{4}{|l|}{ Exercise parameters } \\
\hline METs & $8.5 \pm 2.8$ & $11.1 \pm 3.5$ & $<0.001$ \\
\hline Peak heart rate (bpm) & $147 \pm 24$ & $160 \pm 19$ & $<0.001$ \\
\hline Peak systolic blood pressure (bpm) & $168 \pm 23$ & $165 \pm 24$ & 0.331 \\
\hline Peak diastolic blood pressure (bpm) & $70 \pm 12$ & $73 \pm 12$ & 0.050 \\
\hline
\end{tabular}

\section{Correlates of post-exercise septal $\mathrm{E} / \mathrm{e}^{\prime}$}

With the aim of identifying impaired diastolic reserve from clinical, metabolic and resting echocardiographic parameters, we sought correlates of post-exercise septal $\mathrm{E} / \mathrm{e}^{\prime}$ in the 133 patients with DM. BRCO identified the following clinical correlates (hypertension $(\mathrm{OR}=3.71$, 95\% CI 1.47 to 9.34$)$ and duration of insulin therapy in years $(\mathrm{OR}=1.11,95 \%$ CI 1.04 to 1.19$)$ ), metabolic correlates (HbAlc (OR=1.32, 95\% CI 1.10 to 1.58 ) and eGFR $(\mathrm{OR}=0.98,95 \% \mathrm{CI} 0.97$ to 0.99$)$ ), and echocardiographic 
Table 2 Post-exercise septal E/e' grouped according to resting $\mathrm{E} / \mathrm{e}^{\prime}$ values

\begin{tabular}{|c|c|c|c|}
\hline \multirow{2}{*}{$\begin{array}{l}\text { LV filling pressure } \\
\text { at rest as } \\
\text { indicated by } \\
\text { septal E/e' }\end{array}$} & \multicolumn{2}{|c|}{ Post-exercise septal E/e' } & \multirow[b]{2}{*}{$p$ Value } \\
\hline & $\begin{array}{l}\text { Diabetes } \\
(n=133)\end{array}$ & $\begin{array}{l}\text { No } \\
\text { diabetes } \\
(n=104)\end{array}$ & \\
\hline \multicolumn{4}{|l|}{ Normal } \\
\hline $\begin{array}{l}E / e^{\prime}<8 \\
(n=130)\end{array}$ & $\begin{array}{l}10.3 \pm 3.1 \\
(n=56)\end{array}$ & $\begin{array}{l}7.4 \pm 1.8 \\
(n=74)\end{array}$ & $<0.001$ \\
\hline \multicolumn{4}{|l|}{ Borderline } \\
\hline $\begin{array}{l}E / e^{\prime} 8-15 \\
(n=91)\end{array}$ & $\begin{array}{l}13.0 \pm 2.9 \\
(n=63)\end{array}$ & $\begin{array}{l}9.6 \pm 2.3 \\
(n=28)\end{array}$ & $<0.001$ \\
\hline \multicolumn{4}{|l|}{ Elevated } \\
\hline $\begin{array}{l}E / e^{\prime} \geq 15 \\
(n=16)\end{array}$ & $\begin{array}{l}20.3 \pm 7.4 \\
(n=14)\end{array}$ & $\begin{array}{l}17.4 \pm 3.9 \\
(n=2)\end{array}$ & 0.614 \\
\hline
\end{tabular}

correlates (maximum LA volume index (OR=1.11, 95\% CI 1.05 to 1.17$)$ and $\log$ transformed resting septal $\mathrm{e}^{\prime}$ $(\mathrm{OR}=0.08, \mathrm{p}<0.001))$ to be important correlates of a high post-exercise septal $\mathrm{E} / \mathrm{e}^{\prime}$ ratio in patients with $\mathrm{DM}$. Compared with the base 'clinical model' (AIC=-192.0), metabolic and echocardiographic parameters provided incremental information $(\mathrm{AIC}=-204.3$, and $\mathrm{AIC}=-234.4$, respectively; figure 2 ).

\section{DISCUSSION}

Patients with DM have been shown to have impaired LV diastolic function. ${ }^{12}$ This is also evident in the present study which demonstrated that such patients had a lower resting $\mathrm{e}^{\prime}$ and a higher $\mathrm{E} / \mathrm{e}^{\prime}$ ratio despite a similar $\mathrm{LV}$ mass index. More importantly, in our study, we showed that patients with DM had impaired diastolic reserve, even in those with normal LV filling pressures at rest. They were less able to improve their LV diastolic function and maintain normal LV diastolic pressures with exercise: such patients had a lower $\mathrm{e}^{\prime}$ post-exercise, a lower increase in $\mathrm{e}^{\prime}$ and a higher increase in $\mathrm{E} / \mathrm{e}^{\prime}$, even after adjusting for differences in the resting values. An elevated post-exercise $\mathrm{E} / \mathrm{e}^{\prime}$ is manifest as exertional dyspnoea as evident by its significant relationship with MRC dyspnoea score, not only in all our patients, but also in the subgroup with DM. Furthermore, patients with DM with normal resting $\mathrm{E} / \mathrm{e}^{\prime}$ had a significantly different profile in $\mathrm{e}^{\prime}$ and $\mathrm{E} / \mathrm{e}^{\prime}$ up to 10 min into recovery post-exercise, with the $\mathrm{e}^{\prime}$ remaining significantly lower and $\mathrm{E} / \mathrm{e}^{\prime}$ significantly higher up to $10 \mathrm{~min}$ into recovery after exercise compared with non-DM. Patients with DM with hypertension, longer duration of insulin therapy, worse glycaemic control, worse renal function, larger LA volume and lower septal $\mathrm{e}^{\prime}$ had more impaired diastolic reserve.

\section{$\mathrm{E} / \mathrm{e}^{\prime}$ as a measure of $\mathrm{LV}$ diastolic pressures at rest and post-exercise}

LV filling pressures can be reliably estimated on transthoracic echocardiography from the mitral $\mathrm{E}$ wave
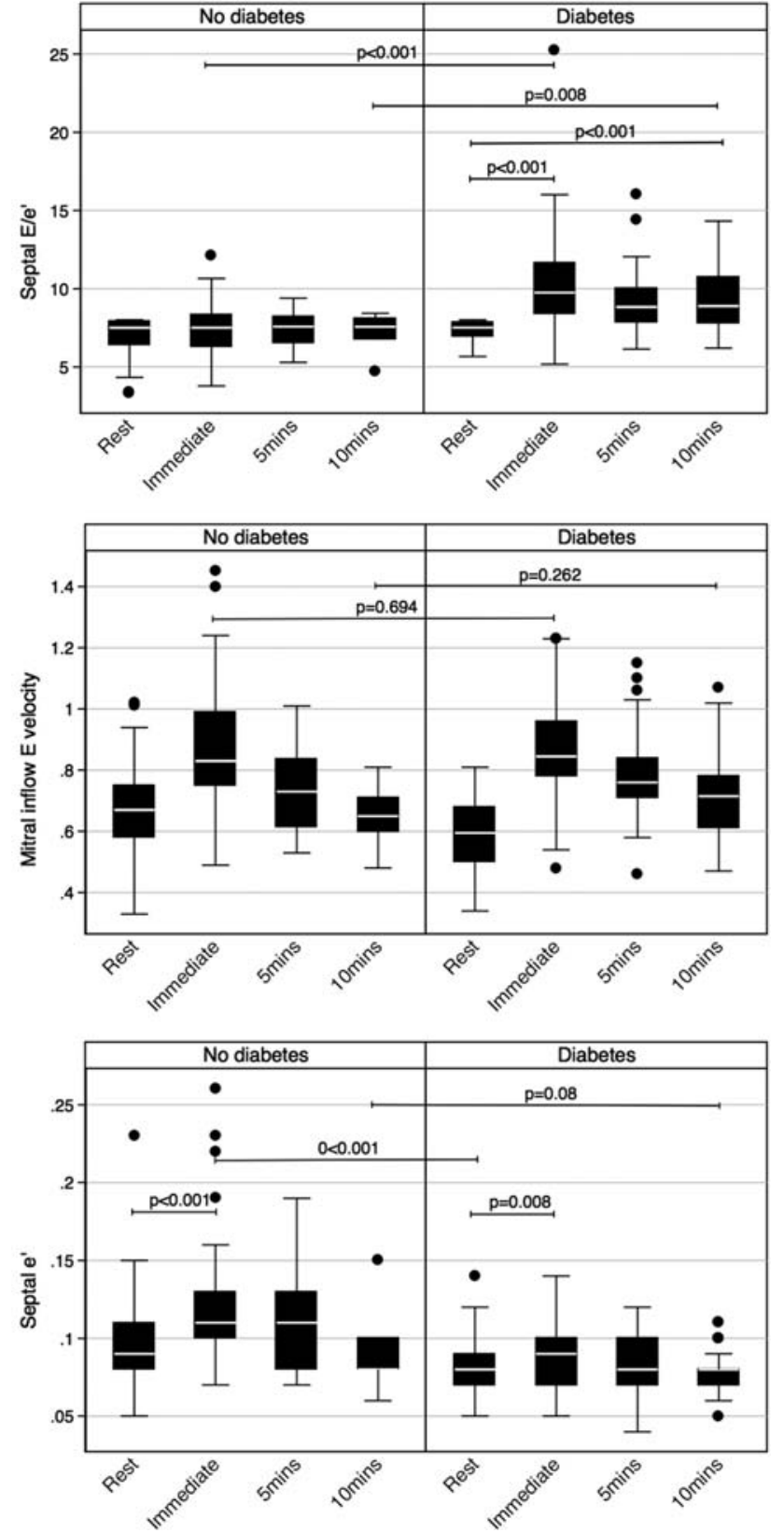

Figure 1 Profile of diastolic function parameters at rest, immediately post-exercise and into recovery. (A) A significant elevation in septal $E / e^{\prime}$ with exercise and into recovery in patients with diabetes mellitus (DM), while septal E/e' remains normal for non-DM. (B) A similar pattern of rise and fall in mitral inflow $E$ wave velocity with exercise in both groups. (C) An increase in septal $e^{\prime}$ in both groups; however, this is significantly more for non-DM.

velocity with pulsed wave tissue Doppler to the mitral annulus tissue Doppler $\mathrm{e}^{\prime}$ velocity ratio. ${ }^{2}$ Unlike the mitral $\mathrm{E}$ wave to $\mathrm{A}$ wave velocity ratio, the $\mathrm{E} / \mathrm{e}^{\prime}$ ratio is age independent and can be used to estimate LV diastolic pressures both in normal and in impaired LV systolic function. A septal $\mathrm{E} / \mathrm{e}^{\prime}$ of $\leq 8$ is generally accepted as indicative of normal diastolic pressures, whereas a septal $\mathrm{E} / \mathrm{e}^{\prime}$ of $\geq 15$ is considered to be indicative of 


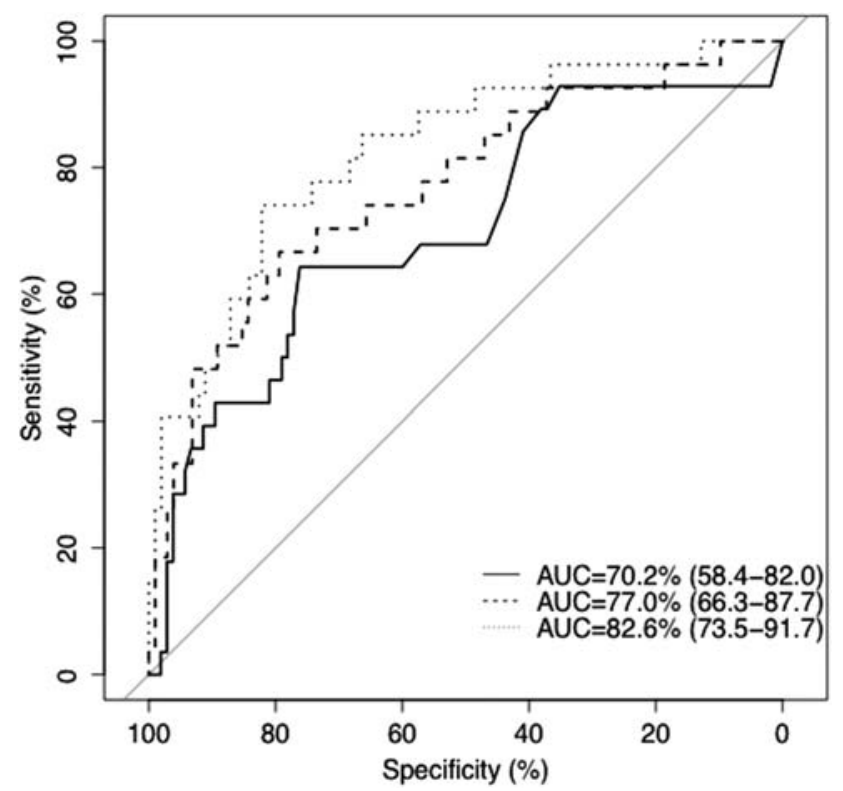

Figure 2 ROC curves for the three different BRCO models in predicting impaired diastolic reserve. The ROC curves for the 'clinical model' (solid line), 'clinical and metabolic model' (dashed line), and 'clinical, metabolic and echocardiographic model' (dotted line) are shown (AUC, area under the curve; BROC, Binary regression with continuous outcomes; ROC, Receiver operating characteristic).

raised diastolic pressures, with a ratio between 8 and 15 being indeterminate. Therefore, in our study, we used a septal $\mathrm{E} / \mathrm{e}^{\prime}$ of $\geq 15$ as the cut-off to avoid any ambiguity.

Septal $\mathrm{E} / \mathrm{e}^{\prime}$ ratio as an indicator of $\mathrm{LV}$ diastolic pressure is not only useful at rest, but has also been shown to be reliable post-exercise. ${ }^{3}{ }^{13}$ Burgess et $a l^{13}$ studied 37 patients who underwent exercise echocardiography on a supine bike with estimation of $\mathrm{E} / \mathrm{e}^{\prime}$ and LV filling pressures simultaneously on cardiac catheterisation. They found good correlation between exercise $\mathrm{E} / \mathrm{e}^{\prime}$ and $\mathrm{LV}$ diastolic pressures with a cut-off of $\mathrm{E} / \mathrm{e}^{\prime} \geq 13$ as indicative of LV end-diastolic pressures of $\geq 15 \mathrm{~mm} \mathrm{Hg}$. In fact, the correlation between $\mathrm{LV}$ diastolic pressures and $\mathrm{E} / \mathrm{e}^{\prime}$ were of a similar magnitude at rest and during exercise. Similar to the study of Burgess et al and others, we used septal $\mathrm{e}^{\prime}$ instead of lateral $\mathrm{e}^{\prime}$, as assessment of lateral $\mathrm{e}^{\prime}$ post-exercise tended to be more unreliable with tachycardia and respiratory motion. ${ }^{1415}$

Exercise $\mathrm{E} / \mathrm{e}^{\prime}$ is of additional diagnostic and prognostic value. An elevated exercise $\mathrm{E} / \mathrm{e}^{\prime}$ was found to be correlated with exercise capacity. ${ }^{13}{ }^{3}$ Holland et al ${ }^{14}$ found that an exercise $\mathrm{E} / \mathrm{e}^{\prime}>14.5$ independently predicted adverse cardiovascular outcome in 538 consecutive patients with normal resting LV systolic function undergoing exercise echocardiography incremental to exercise induced ischaemia. Patients with similar degrees of LV diastolic dysfunction at rest may have very different responses in diastolic function to exercise, and impairment in diastolic response to exercise was correlated with exercise capacity. ${ }^{15}$ Furthermore, assessment of LV diastolic pressure with exercise allowed earlier identification of patients with heart failure with preserved ejection fraction when filling pressures at rest were normal. ${ }^{4}$

\section{Subclinical LV dysfunction in diabetes}

Patients with diabetes may develop LV dysfunction and heart failure independent of traditional risk factors such as hypertension or CAD. Diabetic cardiomyopathy is believed by many to be a clinical entity with multiple pathogenetic mechanisms. ${ }^{16}$ Subclinical systolic and diastolic dysfunction is common in asymptomatic patients with DM in the absence of ischaemia or LV hypertrophy. ${ }^{17}$ Fang et $a l^{18}$ found that subclinical LV dysfunction was associated with poor glycaemic control, advancing age, hypertension and metformin treatment. These factors, with the exception of metformin use, also predicted elevated E/ $\mathrm{e}^{\prime}$ post-exercise in our study. Early detection of diabetic cardiomyopathy is important as earlier detection may allow earlier intervention, which may in turn reverse ventricular dysfunction with improvement in patient outcome. ${ }^{19}$

The MRC dyspnoea scale is a validated measure quantifying the disability associated with breathlessness and correlates well with other dyspnoea scales and walking distance. $^{20} 21$ Its significant relationship with postexercise $\mathrm{E} / \mathrm{e}^{\prime}$ in our patients suggests that elevated $\mathrm{LV}$ filling pressures post-exercise is manifest as exertional dyspnoea. This demonstrates the clinical utility of postexercise $\mathrm{E} / \mathrm{e}^{\prime}$, a marker of $\mathrm{LV}$ diastolic reserve, to evaluate otherwise unexplained exertional dyspnoea.

Examining diastolic reserve in DM may allow even earlier detection of impairment of LV involvement, at a stage where the resting systolic and diastolic function is still comparable to that of normal healthy subjects. Ha et $a l^{22}$ demonstrated a blunted increase in the mitral annular $\mathrm{s}^{\prime}$ and $\mathrm{e}^{\prime}$ velocities in patients with type $2 \mathrm{DM}$ compared with controls despite similar velocities between the two groups at rest. Similar impairment in the increase in $\mathrm{e}^{\prime}$ velocities was noted by Jellis et $a t^{23}$ in patients with DM and normal resting $\mathrm{e}^{\prime}$ velocities. However, LV diastolic pressures as a consequence of inducible LV diastolic dysfunction were not examined in these studies. In this study, we were able to demonstrate that patients with type $2 \mathrm{DM}$ had worse $\mathrm{LV}$ diastolic function and elevated diastolic pressures post-exercise even after controlling for baseline differences. Moreover, the behaviour of LV diastolic function and hence diastolic pressures were distinctly different between patients with $\mathrm{DM}$ and those without, with elevation of $\mathrm{LV}$ diastolic pressures persisting into recovery despite a decrease in the heart rate post-exercise even in the absence of inducible ischaemia. Impaired diastolic reserve is also of prognostic significance. In a study of 197 patients with DM followed up over a median of 57 months, eGFR, $\mathrm{DM}$ duration and the increase in $\mathrm{e}^{\prime}$ with exercise were 
found to be independently predictive of adverse cardiac outcomes. ${ }^{24}$

Other imaging techniques such as cardiac MRI (CMR) are useful in the assessment of diabetic heart disease. Although the temporal resolution of CMR is inferior to echocardiography and evaluation of filling pressures immediately post-exercise may be difficult with $\mathrm{CMR}$, it is useful in tissue characterisation including evaluation of diffuse myocardial fibrosis with T1 mapping and steatosis with spectroscopy. ${ }^{25-27}$

\section{Correlates of impaired diastolic reserve}

Patients with hypertension, longer duration of insulin therapy, poorer glycaemic control, worse renal function, larger LA volume and lower septal $\mathrm{e}^{\prime}$ had more impaired diastolic reserve. It will be of clinical interest to examine whether strict metabolic and blood pressure control, and preservation of renal function may reverse the LV structural and functional derangement seen in patients with type $2 \mathrm{DM}$.

\section{Limitations}

This study is observational in nature, and hence the two groups were not matched for age and gender or presence of cardiovascular risk factors. Patients with DM were more likely to have hypertension, dyslipidemia and obesity, and hence matching these risk factors in patients without diabetes without CAD can be challenging. The proportion of patients with new inducible wall motion abnormalities on exercise echo was low considering the burden of DM in our patients. Exercise echocardiography, with its published sensitivity of detecting CAD of about $80 \%$, might have missed a proportion of patients in our cohort with CAD.

\section{CONCLUSIONS}

Patients with DM have impaired LV diastolic reserve manifest as an inadequate augmentation of their $\mathrm{e}^{\prime}$ response with exercise to leading to an abnormal rise in LV filling pressures. These abnormalities persist up to $10 \mathrm{~min}$ into the recovery period despite recovery of heart rate. Patients with DM with hypertension, longer duration of insulin therapy, poorer glycaemic control, worse renal function, larger LA volume and lower septal $\mathrm{e}^{\prime}$ had more impaired diastolic reserve. Detection of impaired diastolic reserve in patients with normal resting LV function may allow earlier detection of diabetic cardiomyopathy.

Contributors ML jointly conceived the study with DYL, as well as designed and implemented the trial, obtained ethics approval and prepared the manuscript. ML, VP, VWW and MW were involved in the recruitment of participants, testing of trial patients and data collection. SH and ML performed statistical analysis.

Funding ML was supported by an Australian National Health and Medical Research Council Postgraduate funding.
Competing interests None declared.

Patient consent Obtained.

Ethics approval Sydney Southwest Area Health Research Ethics Committee.

Provenance and peer review Not commissioned; externally peer reviewed.

Open Access This is an Open Access article distributed in accordance with the Creative Commons Attribution Non Commercial (CC BY-NC 4.0) license, which permits others to distribute, remix, adapt, build upon this work noncommercially, and license their derivative works on different terms, provided the original work is properly cited and the use is non-commercial. See: http:// creativecommons.org/licenses/by-nc/4.0/

\section{REFERENCES}

1. Galderisi M. Diastolic dysfunction and diabetic cardiomyopathy: evaluation by Doppler echocardiography. J Am Coll Cardiol 2006;48:1548-51.

2. Nagueh SF, Appleton CP, Gillebert TC, et al. Recommendations for the evaluation of left ventricular diastolic function by echocardiography. J Am Soc Echocardiogr 2009;22:107-33.

3. Ha JW, Oh JK, Pellikka PA, et al. Diastolic stress echocardiography: a novel noninvasive diagnostic test for diastolic dysfunction using supine bicycle exercise Doppler echocardiography. J Am Soc Echocardiogr 2005;18:63-8.

4. Borlaug BA, Nishimura RA, Sorajja P, et al. Exercise hemodynamics enhance diagnosis of early heart failure with preserved ejection fraction. Circ Heart Fail 2010;3:588-95.

5. Holland DJ, Prasad SB, Marwick TH. Contribution of exercise echocardiography to the diagnosis of heart failure with preserved ejection fraction (HFpEF). Heart 2010;96:1024.

6. Fletcher CM, Elmes PC, Fairbairn AS, et al. Significance of respiratory symptoms and the diagnosis of chronic bronchitis in a working population. BMJ 1959;2:257.

7. Levey AS, Bosch JP, Lewis JB, et al. A more accurate method to estimate glomerular filtration rate from serum creatinine: a new prediction equation. Ann Intern Med 1999;130:461-70.

8. Suissa S, Blais L. Binary regression with continuous outcomes. Stat Med 1995;14:247-55.

9. Heritier S, Ronchetti E. Robust binary regression with continuous outcomes. Can J Stat 2004;32:239-49.

10. Steyerberg EW, Vickers AJ, Cook NR, et al. Assessing the performance of prediction models: a framework for some traditional and novel measures. Epidemiology 2010;21:128.

11. National_Kidney_Foundation. K/DOQI clinical practice guidelines for chronic kidney disease: evaluation, classification, and stratification. Am J Kidney Dis 2002;39:S1-266.

12. From AM, Scott CG, Chen HH. Changes in diastolic dysfunction in diabetes mellitus over time. Am J Cardiol 2009;103:1463-6.

13. Burgess MI, Jenkins C, Sharman JE, et al. Diastolic stress echocardiography: hemodynamic validation and clinical significance of estimation of ventricular filling pressure with exercise. J Am Coll Cardiol 2006;47:1891-900.

14. Holland DJ, Prasad SB, Marwick TH. Prognostic implications of left ventricular filling pressure with exercise. Circ Cardiovasc Imaging 2010;3:149-56.

15. Ha JW, Choi D, Park S, et al. Left ventricular diastolic functional reserve during exercise in patients with impaired myocardial relaxation at rest. Heart 2009;95:399-404.

16. Boudina S, Abel ED. Diabetic cardiomyopathy, causes and effects. Rev Endocr Metab Disord 2010;11:31-9.

17. Fang ZY, Schull-Meade R, Leano R, et al. Screening for heart disease in diabetic subjects. Am Heart J 2005;149:349-54.

18. Fang ZY, Schull-Meade R, Downey M, et al. Determinants of subclinical diabetic heart disease. Diabetologia 2005;48:394-402.

19. Picano E. Diabetic cardiomyopathy. The importance of being earliest. J Am Coll Cardiol 2003;42:454-7.

20. Meek P, Schwartzstein R, Adams L, et al. Dyspnea-mechanisms, assessment, and management: a consensus statement. $A m \mathrm{~J}$ Respir Crit Care Med 1999;159:321-40.

21. Stenton C. The MRC breathlessness scale. Occup Med (Lond) 2008;58:226-7.

22. Ha JW, Lee HC, Kang ES, et al. Abnormal left ventricular longitudinal functional reserve in patients with diabetes mellitus: 
implication for detecting subclinical myocardial dysfunction using exercise tissue Doppler echocardiography. Heart 2007;93:1571-6.

23. Jellis CL, Stanton T, Leano R, et al. Usefulness of at rest and exercise hemodynamics to detect subclinical myocardial disease in type 2 diabetes mellitus. Am J Cardiol 2011;107:615-21.

24. Kim SA, Shim CY, Kim JM, et al. Impact of left ventricular longitudinal diastolic functional reserve on clinical outcome in patients with type 2 diabetes mellitus. Heart 2011;97:1233.
25. Ng AC, Delgado V, Bertini M, et al. Myocardial steatosis and biventricular strain and strain rate imaging in patients with type 2 diabetes mellitus. Circulation 2010;122:2538-44.

26. Rijzewijk LJ, van der Meer RW, Smit JW, et al. Myocardial steatosis is an independent predictor of diastolic dysfunction in type 2 diabetes mellitus. J Am Coll Cardiol 2008;52:1793-9.

27. Korosoglou G, Humpert PM, Ahrens J, et al. Left ventricular diastolic function in type 2 diabetes mellitus is associated with myocardial triglyceride content but not with impaired myocardial perfusion reserve. J Magn Reson Imaging 2012;35:804-11. 